\title{
Gardner syndrome with giant abdominal desmoid tumor during pregnancy: a case report
}

\author{
Liquan Jin' ${ }^{1}$, Yunbo Tan ${ }^{1}$, Ziting Su', Shan Huang ${ }^{1}$, Sita Pokhrel ${ }^{2}$, Hongbo Shi ${ }^{1}$ and Yiming Chen ${ }^{1,3^{*}}$ (0)
}

\begin{abstract}
Background: Gardner syndrome is a subtype of familial adenomatous polyposis (FAP), characterized by a combination of adenomatous intestinal polyps and extracolonic lesions such as multiple osteomas, dental abnormalities, and soft tissue tumors. Although $12 \%$ of patients with intestinal polyposis of FAP may occur intra-abdominal desmoid tumors, pregnancy complicating with giant abdominal desmoid tumors is a relatively rare case.

Case presentation: A 28-year-old pregnant woman was diagnosed with Gardner syndrome in whom an intraabdominal tumor was found a year after undergoing a laparoscopic total colectomy due to family adenomatous polyposis. At 32 weeks' gestation, she presented to our department for the third time complaining upper abdominal pain caused by the giant abdominal mass about $21 \times 12 \mathrm{~cm}^{2}$ in size. After multidisciplinary consultation and discussion, the decision of fetal preservation treatment was made. After the delivery of a baby girl, abdominal mass resection was performed, and pathological examination revealed a fibrous adenoma. The patient was discharged after a week and was uneventful in the follow-up for half a year.

Conclusions: Gardner syndrome is characterized by typical syndrome including family adenomatous polyposis and extra-intestinal tissue tumor. Were desmoid tumors rarely as large as fetus and local aggressively. In our case, we selected surgery to remove the intra-abdominal desmoid tumor after the natural delivery of the fetus and no abnormalities were observed during the 6 months follow-up. Women during pregnancy have an increased risk for the development of desmoid tumors, likely with the sex hormone to be one of the triggers. Therefore, we suggested that when a patient with Gardner syndrome desire to conceive again, they should go to the hospital for a regular review at least once every 3 months.
\end{abstract}

Keywords: Gardner syndrome, Desmoid tumor, FAP, Pregnancy, Case report

\section{Background}

Gardner syndrome, mainly manifested by multiple gastrointestinal polyps and universal lesions such as soft tissue tumor, ectopic teeth, osteoma, and retinal pigment epithelium, is a rare autosomal dominant genetic disorder caused by gene mutation in adenomatous polyposis coli (APC). Occasionally, Gardner syndromes also known as "deep" or "invasive" fibromatosis, characterized by

\footnotetext{
*Correspondence: drchenyiming@gmail.com

1 1St Department of General Surgery, The First Affiliated Hospital of Dali

University, 32 Carlsberg Ave, Dali 671000, Yunnan, China

Full list of author information is available at the end of the article
}

fibroblastomas or desmoid tumors that originated from deep muscle or aponeurosis.

The World Health Organization (WHO) classified desmoid tumors as one of the moderate fibroblastoma, which recurs locally and invasively rather than distant metastasis. The incidence of Gardner syndrome is 2-4 per million globally, more in females. Moreover, a few factors were identified to be responsible for desmoid tumor: surgery history, trauma, oral contraceptives, reproductive age and delivery history. To diagnose the desmoid tumor, spindle cells in the dense collagen stroma while rare mitosis and necrosis could be found under histopathological examination. In this paper, we report

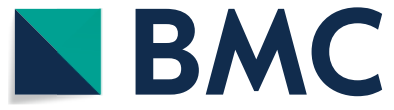

(C) The Author(s) 2020. Open Access This article is licensed under a Creative Commons Attribution 4.0 International License, which permits use, sharing, adaptation, distribution and reproduction in any medium or format, as long as you give appropriate credit to the original author(s) and the source, provide a link to the Creative Commons licence, and indicate if changes were made. The images or other third party material in this article are included in the article's Creative Commons licence, unless indicated otherwise in a credit line to the material. If material is not included in the article's Creative Commons licence and your intended use is not permitted by statutory regulation or exceeds the permitted use, you will need to obtain permission directly from the copyright holder. To view a copy of this licence, visit http://creativecommons.org/licenses/by/4.0/. The Creative Commons Public Domain Dedication waiver (http://creativeco mmons.org/publicdomain/zero/1.0/) applies to the data made available in this article, unless otherwise stated in a credit line to the data. 
a case of Gardner syndrome in a female with a giant abdominal desmoid tumor during pregnancy.

\section{Case presentation}

A 28-year-old female, gravida 2, para 1, discovered a massive mass in the abdominal cavity during the 8 th month of pregnancy. Three years ago, this patient was admitted to our hospital in the Hematology and Oncology Department due to "repeated dizziness, fatigue and shortness of breath after activity". She was admitted at $60 \mathrm{~g} / \mathrm{L}$ hemoglobin and was transfused with $3.0 \mathrm{U}$ of the same type of red blood cell suspension. The microscopic examination of colon revealed extensive polyp-like lesions in the entire colon. On-duty doctor in responsible for this case suspected "familial adenomatous polyposis (FAP)" and suggested transfer of this patient to our surgical department for further evaluation and treatment. After completing the preoperative examination and investigation, a laparoscopic total colectomy was performed. Postoperative pathological examination showed tubular adenomas (low-grade) and more than 1000 polyps, most of which were broad-based and fit the family adenomatous polyposis. One year later, fibroid adenoma was found in the upper right pubic symphysis. Taking the intestinal lesions into consideration, this case was diagnosed as "Gardner syndrome". In August 2019, the patient presented for the third time to our hospital due to upper abdominal pain at 32 weeks of pregnancy. A CT examination showed that the left side of the uterus in the abdominal cavity was occupied by a huge mass about $21 \times 12 \mathrm{~cm}$ in size, with mild hydronephrosis in both kidneys (Fig. 1). The patient was diagnosed with abdominal mass with intrauterine pregnancy at 31 weeks with bilateral hydronephrosis. After multidisciplinary consultation and discussion at our hospital, the decision of fetal preservation treatment was made. In October 2019, 1 month after the delivery of a baby girl, the patient still looked like as pregnant according to the abdominal appearance (Fig. 2). An 'Extreme mass Abdominal Mass Resection' was performed at our department (Figs. 3, 4). The postoperative pathological examination showed that the ligament-like fibrous adenoma (Fig. 5), combined with the medical history, met the diagnosis criteria of Gardner Syndrome. The patient was discharged after one week and no abnormality was found in the follow-up for half a year.

\section{Discussion and conclusion}

Gardner syndrome is characterized not only by typical syndrome including family adenomatous polyposis and extra-intestinal tissue tumor but also by a rare presentation with giant abdominal desmoid tumors during pregnancy [1]. The desmoid tumor can be as large as a fetus and the tumor can be locally aggressive, so it

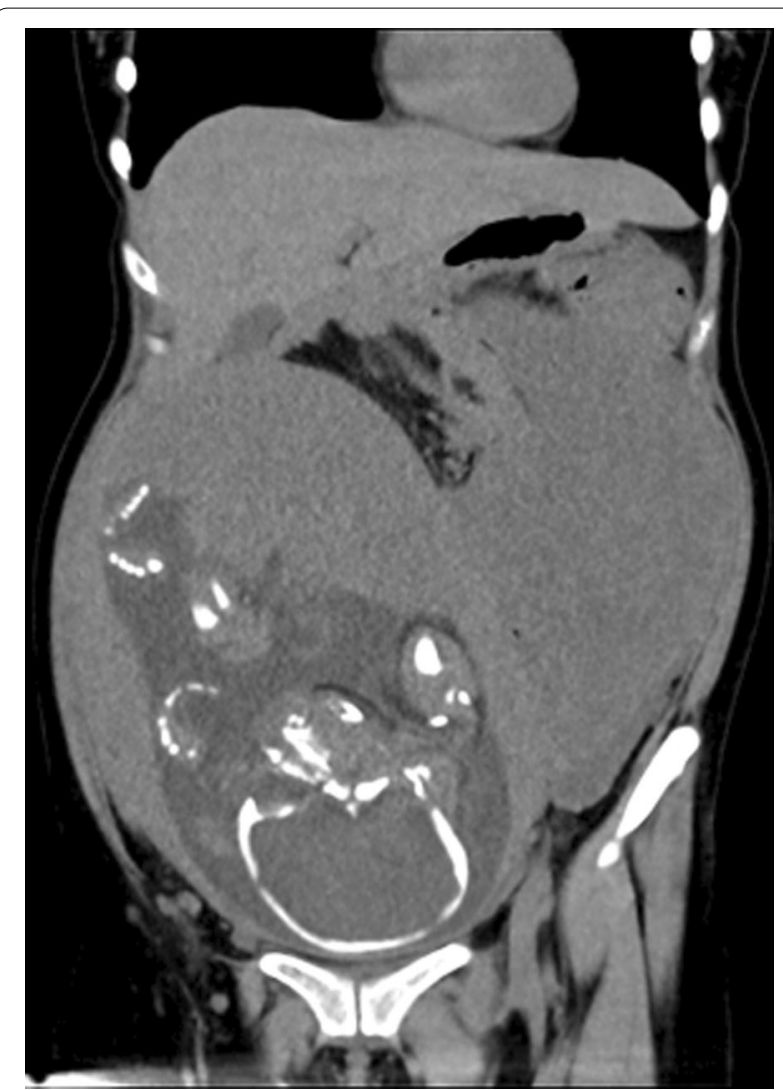

Fig. 1 CT scanning showed a huge occupant in left side, abdominal cavity and the fetal in the right with 31 weeks

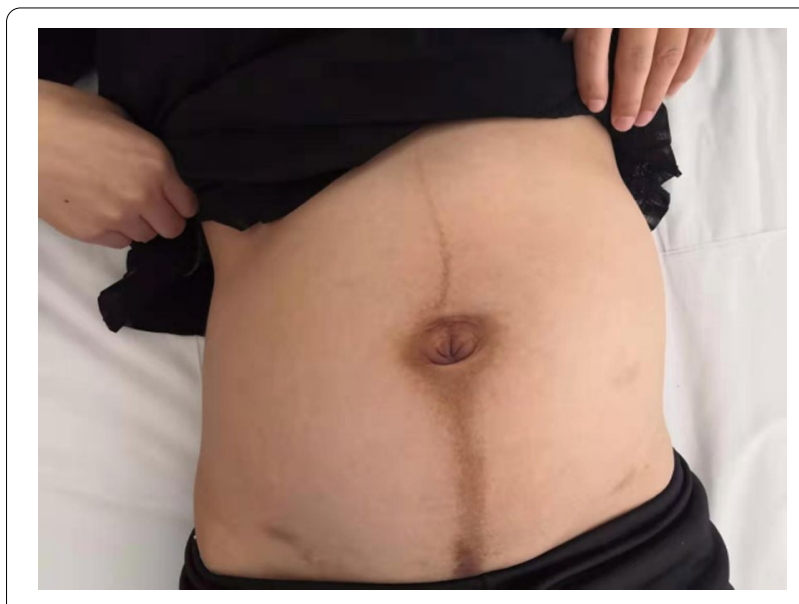

Fig. 2 One month after delivery, the abdomen is visible as pregnant

is hard to decide for the available treatment options. In our case, although the celiac desmoid tumor was huge, the fetus was in good condition without intrauterine distress or hypoxia and the fetus development was normal. Therefore, after the natural delivery of the fetus, an 


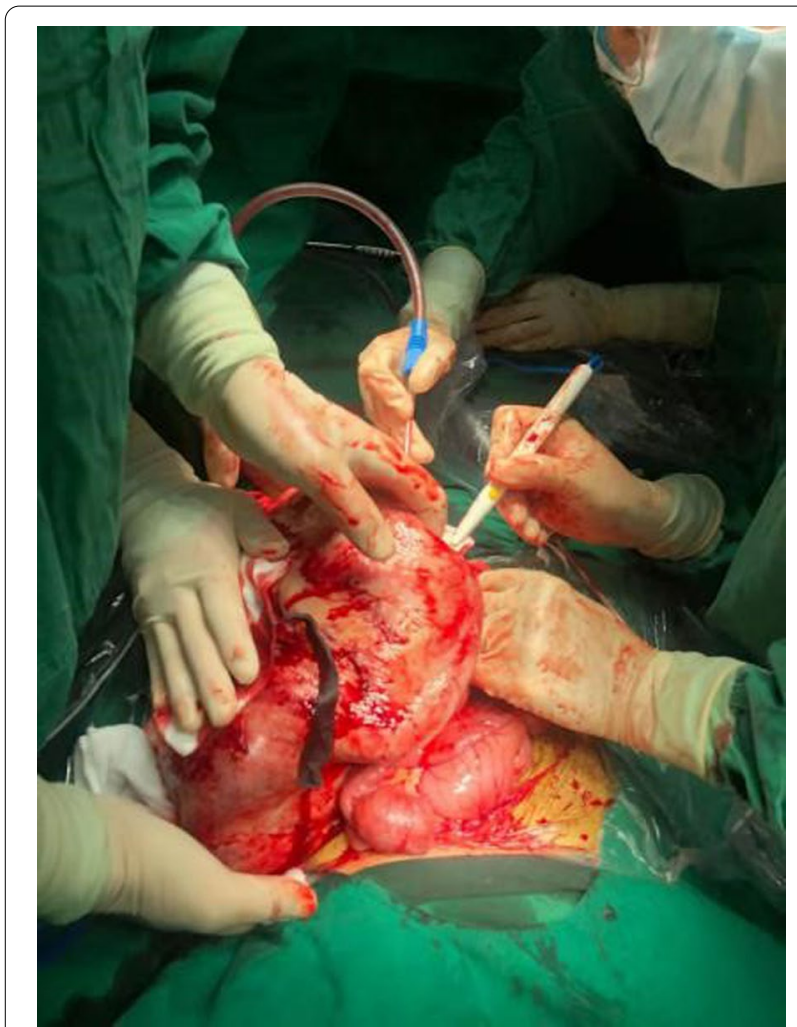

Fig. 3 Surgery section the huge abdominal mass

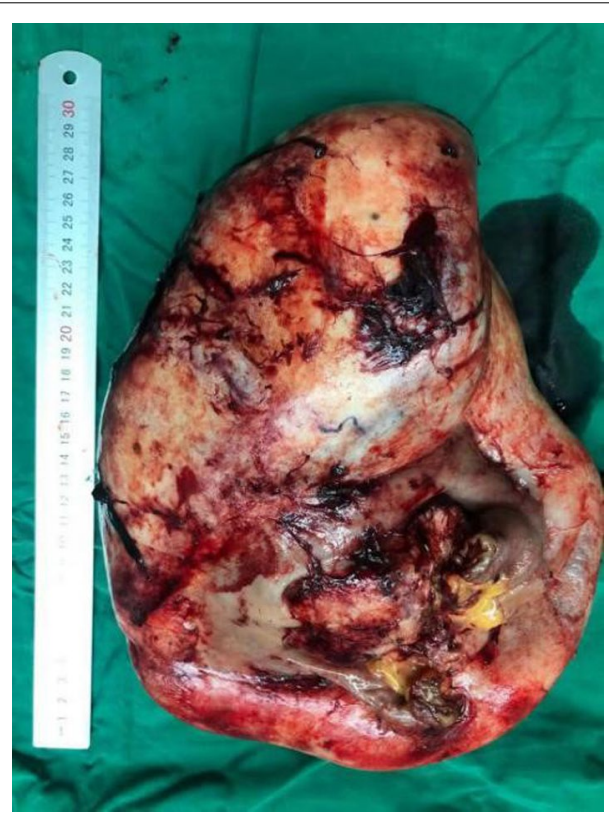

Fig. 4 Removal of specimen $\left(30 \mathrm{~cm}^{*} 15 \mathrm{~cm} * 5 \mathrm{~cm}\right)$

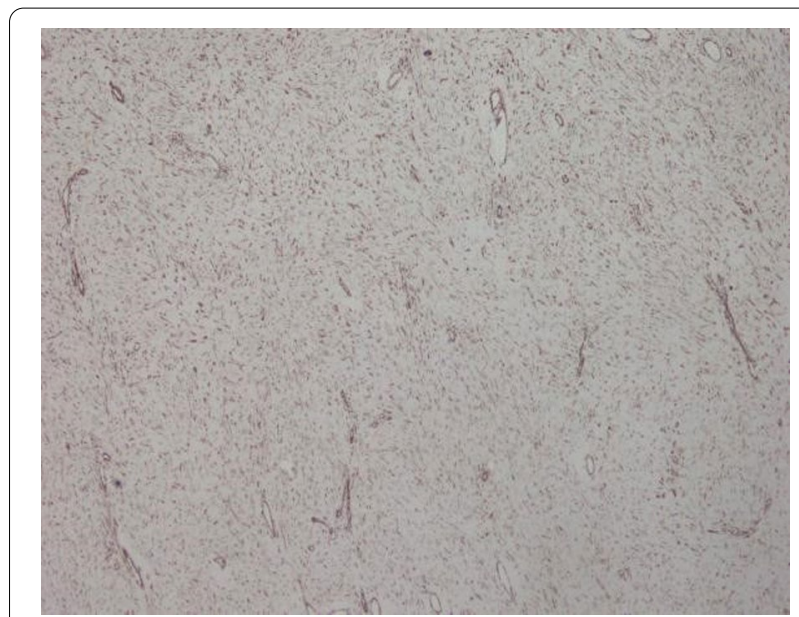

Fig. 5 Postoperative pathological examination showed ligament-like fibrous adenoma

operation to remove the desmoid tumor is an appropriate treatment option to avoid fetal dyspnea, dysplasia, and increased maternal mortality. Early operation to prevent local desmoid infiltration and mesenteric desmoid tumors, which is the second leading cause of mortality in FAP patients [2], would have increased the maternal mortality risk. The localization of desmoid tumors is generally classified as intra-abdominal in the abdominal wall or extra-abdominal [3]. Desmoid tumors most commonly involve the extra-abdominal locations in the general population, whereas patients with FAP mostly present with intraabdominal disease. Only $5 \%$ of sporadic desmoid tumors are intra-abdominal, but $80 \%$ of patients with familial adenomatous polyposis (FAP)-associated desmoid tumors develop intra-abdominal disease [4]. The incidence is $3 \%$ for soft tissue sarcomas and about $0.03 \%$ for all malignancies [5].

Gardner's syndrome is associated with familial adenomatous polyposis (FAP), involving a mutation in anaphase promoting complex gene and several extradigestive manifestations: osteomas, epidermal cysts and desmoid tumors [6]. Approximately $7.5 \%$ of desmoid tumors are associated with familial adenomatous polyposis (FAP) in the general population. There is a special relationship between desmoids and FAP (Gardner syndrome), with an incidence of 3.5-32\% [7]. The usual presentation is a slowly growing mass without associated pain or discomfort. Depending on the location of the tumor, it may present with symptoms such as neurological deficit, joint stiffness or abdominal complaints. In our case, the patient complained of abdominal pain during pregnancy. Despite the significant size of the mass, the abdominal pain was not so severe, hence, the patient presented for delayed consultation. As a result, the fetal 
growth during pregnancy can be overlooked with the presence of abdominal masses. Moreover, failure to recognize Gardner syndrome combined with familial intestinal polyps resulted in the growth of desmoid tumors in the abdominal cavity. Therefore, we suggested that when a patient with an age of below 30 with FAP and the history of extra-abdominal desmoid tumors, the possibility of intraperitoneal desmoid tumor growth should be taken into consideration. If the patient desire to conceive again, they should go to the hospital for a regular review at least once every 3 months.

Although the mechanism of desmoid tumors remains largely unknown, desmoid tumors might be driven by alterations of the Wnt/APC/ $\beta$-catenin pathway [8], e.g., sporadic desmoid tumors are associated with somatic mutations of CTNNB1, and germline mutations of APC and somatic mutations of CTNNB1 are probably mutually exclusive. The rate of cases diagnosed with core-needle biopsies and CTNNB1 mutational analysis increased from 30.6 to $40.7 \%$ and from 87.8 to $94.1 \%$, respectively. The mean delayed for pathological diagnosis confirmation constantly decreased from 107 to 47 days [9]. In addition, hormonal, genetic and physical factors all play a role in the development and growth of desmoid tumors. Desmoids occur between the age of 15 and 60 years, but particularly during early adolescence and with a peak age of about 30 years. Women during pregnancy have an increased risk for the development of desmoid tumors $[3,10,11]$, likely with the sex hormone to be one of the triggers.

Regarding the treatment of desmoid tumors, new alternatives emerged especially in primary non-resectable locations in recent years. Initially, local surgery is the first chosen treatment for desmoid tumors. With advanced techniques, large en bloc surgery is no longer regarded as a cornerstone treatment for desmoid tumors, given that the relapse rate after surgery exceeds $60 \%$ in larger series, and that spontaneous regression is documented to be approximately $25 \%$ of the cases [12]. Therefore, there is a current shift to a more conservative approach, namely the 'wait-and-see policy' [13], which is currently recommended as the first approach in Desmoid-type fibromatosis (DTF) [14]. However, a nationwide prospective cohort [15] showed that there was no difference between patients undergoing an operation and those managed by the wait-and-see policy in terms of two years of eventfree survival (EFS). Among the patients with favorable locations (abdominal wall, breast, intra-abdominal and lower limb), the 2-year EFS was similar in patients treated by either surgery or the wait-and-see approach. Among patients with unfavorable locations (chest wall, head and neck and upper limb), the 2-year EFS was significantly enhanced in patients initially managed with the wait-and-see approach compared with those who underwent initial surgery. Nevertheless, systematic therapy is an option in unresectable or recurrent diseases. Available options include hormonal therapies, non-steroidal antiinflammatory drugs (NSAIDs), interferon, and chemotherapy. The use of hormonal therapy for the treatment of these tumors is based on the association of these tumors with pregnancy or contraceptives pills and reports of regression after menopause or oophorectomy. Success rates of around $50 \%$ have been obtained with hormonal treatments and other agents such as NSAIDs, Vitamin C and warfarin. The most common regimen uses high dose tamoxifen at $120 \mathrm{mg}$ per day along with sulindac and chemotherapy (imatinib and doxorubicin) [16]. In our case, we selected surgery to remove the intra-abdominal desmoid tumor after the natural delivery of the fetus and no abnormalities were observed during the 6 months follow-up. Women during pregnancy have an increased risk for the development of desmoid tumors, likely with the sex hormone to be one of the triggers. Therefore, we suggested that when a patient with Gardner syndrome desire to conceive again, they should go to the hospital for a regular review at least once every 3 months.

\section{Abbreviations \\ FAP: Familial adenomatous polyposis; APC: Adenomatous polyposis coli; WHO: World Health Organization; CT: Computed tomography; CTNNB1: A protoon- cogene gene encodes for b-catenin; DTF: Desmoid-type fibromatosis; EFS: Event-free survival; NSAIDs: Non-steroidal anti-inflammatory drugs.}

\section{Acknowledgements}

Not applicable.

\section{Authors' contributions}

YMC initiated the research and drafted the manuscript. LQJ drafted the manuscript. YBT, ZTS and HBS took care of the patient and performed the surgery. $\mathrm{SH}$ analyzed the data and assisted in the preparation of the manuscript. SP checked the language issues. All authors have read and approved the publishment of the manuscript.

\section{Funding}

Not applicable.

\section{Availability of data and materials Not applicable.}

\section{Ethics approval and consent to participate}

This case report was approved by the Ethics Committee of The First Affiliated Hospital of Dali University, and written informed consent was obtained from the patient.

\section{Consent for publication}

Written informed consent was obtained from the patient for publication of this case report and any accompanying images.

\section{Competing interests}

The authors declare that they have no competing interests.

\section{Author details}

1 1St Department of General Surgery, The First Affiliated Hospital of Dali University, 32 Carlsberg Ave, Dali 671000, Yunnan, China. ${ }^{2}$ Universal College 
of Medical Sciences, Bhairahawa, Nepal. ${ }^{3}$ Institute of Translational Medicine for Metabolic Diseases, Dali University, Dali, Yunnan Province, China.

Received: 27 July 2020 Accepted: 3 November 2020

Published online: 12 November 2020

\section{References}

1. Golant A, Zeichner JA. Gardner syndrome. In: Joshua A, Zeicher MD, editors. Acneiform eruptions in dermatology. New York, NY: Springer; 2014. p. 201-6.

2. Sinha A, Tekkis PP, Gibbons DC, Phillips RK, Clark SK. Risk factors predicting desmoid occurrence in patients with familial adenomatous polyposis: a meta-analysis. Colorectal Dis. 2011;13(11):1222-9.

3. Shinagare AB, Ramaiya NH, Jagannathan JP, Krajewski KM, Giardino AA, Butrynski JE, Raut CP. A to Z of desmoid tumors. Am J Roentgenol. 2011;197(6):W1008-14.

4. Jenayah AA, Bettaieb H, Saoudi S, Gharsa A, Sfar E, Boudaya F, Chelli D. Desmoid tumors: clinical features and treatment options: a case report and a review of literature. Pan Afr Med J. 2015;21:93.

5. Lazar AJ, Tuvin D, Hajibashi S, Habeeb S, Bolshakov S, Mayordomo-Aranda E, Warneke CL, Lopez-Terrada D, Pollock RE, Lev D. Specific mutations in the $\beta$-catenin gene (CTNNB1) correlate with local recurrence in sporadic desmoid tumors. Am J Pathol. 2008;173(5):1518-27.

6. Guignard N, Cartier C, Crampette L, Akkari M. Gardner's syndrome presenting with a fibromatous tumour of the parotid. Eur Ann Otorhinolaryngol Head Neck Dis. 2016;133(5):357-9.

7. Alman BA, Pajerski ME, Diaz-Cano S, Wolfe HJ. Aggressive fibromatosis (desmoid tumor) is A. Diagn Mol Pathol. 1997;6(2):98-101.

8. Penel N, Chibon F, Salas S. Adult desmoid tumors: biology, management and ongoing trials. Curr Opin Oncol. 2017;29(4):268.

9. Penel N, Coindre JM, Bonvalot S, Italiano A, Neuville A, Le Cesne A, Terrier P, Ray-Coquard I, Ranchere-Vince D, Robin YM, Isambert N. Management of desmoid tumours: a nationwide survey of labelled reference centre networks in France. Eur J Cancer. 2016;1 (58):90-6.

10. Awwad J, Hammoud N, Farra C, Fares F, Abi Saad G, Ghazeeri G. Abdominal wall desmoid during pregnancy: diagnostic challenges. Case Rep Obstetr Gynecol. 2013. https://doi.org/10.1155/2013/350894.

11. Durkin AJ, Korkolis DP, Al-Saif O, Zervos EE. Full-term gestation and transvaginal delivery after wide resection of an abdominal desmoid tumor during pregnancy. J Surg Oncol. 2005;89(2):86-90.

12. Crago AM, Denton B, Salas S, Dufresne A, Mezhir JJ, Hameed M, Gonen $M$, Singer S, Brennan MF. A prognostic nomogram for prediction of recurrence in desmoid fibromatosis. Ann Surg. 2013;258(2):347.

13. Bonvalot S, Eldweny H, Haddad V, Rimareix F, Missenard G, Oberlin O, Vanel D, Terrier P, Blay JY, Le Cesne A, Le Péchoux C. Extra-abdominal primary fibromatosis: aggressive management could be avoided in a subgroup of patients. Eur J Surg Oncol (EJSO). 2008;34(4):462-8.

14. Fiore M, Rimareix F, Mariani L, Domont J, Collini P, Le Péchoux C, Casali PG, Le Cesne A, Gronchi A, Bonvalot S. Desmoid-type fibromatosis: a frontline conservative approach to select patients for surgical treatment. Ann Surg Oncol. 2009;16(9):2587-93.

15. Penel N, Le Cesne A, Bonvalot S, Giraud A, Bompas E, Rios M, Salas S, Isambert N, Boudou-Rouquette P, Honore C, Italiano A. Surgical versus non-surgical approach in primary desmoid-type fibromatosis patients: a nationwide prospective cohort from the French Sarcoma Group. Eur J Cancer. 2017;1(83):125-31.

16. Barbier O, Anract P, Pluot E, Larouserie F, Sailhan F, Babinet A, Tomeno B. Primary or recurring extra-abdominal desmoid fibromatosis: assessment of treatment by observation only. Orthopaed Traumatol. 2010;96(8):884-9

\section{Publisher's Note}

Springer Nature remains neutral with regard to jurisdictional claims in published maps and institutional affiliations.
Ready to submit your research? Choose BMC and benefit from:

- fast, convenient online submission

- thorough peer review by experienced researchers in your field

- rapid publication on acceptance

- support for research data, including large and complex data types

- gold Open Access which fosters wider collaboration and increased citations

- maximum visibility for your research: over $100 \mathrm{M}$ website views per year

At BMC, research is always in progress.

Learn more biomedcentral.com/submissions 